\title{
Peripheral Arterial Disease and Its Associated Factors among Type 2 Diabetes Mellitus Patients at Debre Tabor General Hospital, Northwest Ethiopia
}

\author{
Yonas Akalu $\mathbb{D}^{1}$ and Ambaye Birhan ${ }^{2}$ \\ ${ }^{1}$ Department of Physiology, College of Medicine and Health Sciences, University of Gondar, Gondar, Ethiopia \\ ${ }^{2}$ Department of Radiology, College of Medicine and Health Sciences, Debre Tabor University, Debre Tabor, Ethiopia \\ Correspondence should be addressed to Yonas Akalu; yonasakalu21@gmail.com
}

Received 20 November 2019; Accepted 18 January 2020; Published 29 January 2020

Academic Editor: Eric Hajduch

Copyright (c) 2020 Yonas Akalu and Ambaye Birhan. This is an open access article distributed under the Creative Commons Attribution License, which permits unrestricted use, distribution, and reproduction in any medium, provided the original work is properly cited.

\begin{abstract}
Background. Peripheral arterial disease (PAD), one of the major macrovascular complications of diabetes, is associated with cardiovascular mortality and a high rate of disability following the amputation of an extremity in diabetes patients. However, there is no data on the prevalence of PAD among type 2 diabetes patients in Ethiopia. Therefore, the current study is aimed at determining the prevalence and associated factors of PAD among type 2 diabetes patients at Debre Tabor General Hospital, Debre Tabor, Northwest Ethiopia. Methods. An institution-based cross-sectional study was conducted among type 2 diabetes mellitus patients from February 1 to August 30, 2019. A pretested interviewer-administered questionnaire was used to collect the data. The presence of stenosis and its grading were determined by color Doppler ultrasonography. Data were entered using EpiData-V.4.6 and analyzed by STATA-14. Bivariable and multivariable logistic regression was performed to identify associated factors of peripheral arterial disease. Adjusted odds ratio (AOR) and its confidence interval were estimated for potential predictors included in the final model. $P \leq 0.05$ was used to declare statistical significance. Results. The mean age of the study participants was $61.2 \pm 7.3$ years. One hundred seventy-two (61.4\%) patients were males. The prevalence of PAD in this study was 30.7\% (95\% CI (25.3-36.2\%)). Of these, 37 (43\%) were symptomatic. Age (AOR = 1.09, 95\% CI (1.03-1.16)), higher HbAlc $(\mathrm{AOR}=1.97,95 \% \mathrm{CI}(1.03-3.40))$, being an ex-smoker $(\mathrm{AOR}=4.68,95 \%$ CI $(1.93-11.30))$, and current cigarette smoking $(\mathrm{AOR}=5.84,95 \%$ CI (1.79-19.04)) were significantly associated with PAD. Conclusion. The prevalence of peripheral arterial disease among type 2 diabetes patients was high. Increasing age, high $\mathrm{HbAlc}$, and being cigarette smokers increase the likelihood of developing peripheral arterial disease. Clinicians should prevent PAD; screen T2DM patients who are aged, with high HbAlc, and cigarette smokers; and treat them timely.
\end{abstract}

\section{Background}

Diabetes is a complex chronic metabolic disorder, requiring continuous medical care with multifactorial risk reduction strategies, characterized by persistent hyperglycemia because of lack of insulin secretion, insulin resistance, or both $[1,2]$. Its prevalence is steadily increasing in the world, most markedly in the lower- and middle-income countries $[2,3]$ like Ethiopia, which is the first among the top five countries of Africa for a number of people with diabetes [4]. Through time, T2DM leads to early microcomplications, peripheral neuropathy, peripheral retinopathy, and peripheral nephropathy, and late macrocomplications, which are a consequence of atherosclerosis of the arteries, including peripheral arterial disease, coronary artery disease, and cerebrovascular accident which all are potentially life-threatening $[5,6]$. Among these, peripheral arterial disease (PAD) is one of the major complications of diabetes. Peripheral arterial disease is defined as an atherosclerotic narrowing of peripheral arteries of the legs, stomach, arms, and the head-most commonly involving arteries of lower extremities $[7,8]$. It is a major complication of atherosclerosis [8] as well as a manifestation 
of atherosclerosis in major blood vessels like coronary and cerebral arteries $[9,10]$. It results in systemic atherothrombosis that leads to cerebrovascular events, including myocardial infarction, stroke, significant long-term disability, and death [9, 11-13]. Diabetic patients with PAD are at high risk of increased morbidity and mortality from cardiovascular diseases and a high rate of lower extremity amputation $[7,14-16]$. This increased risk of amputation in diabetes patients is due to dry gangrene [17], end-stage presentation of PAD, and foot ulcer secondary to PAD [18]. Almost two-thirds of diabetic patients with foot ulcers have PAD, which is associated with a high amputation rate and mortality [19]. The prevalence of PAD is 3 to 4 times higher and severe in diabetic individuals compared with nondiabetic individuals $[11,20-22]$. The global prevalence of PAD is estimated to be 202 million [23, 24]. Twelve percent of the adult population has PAD [25]. A study in Korea revealed that the prevalence of PAD among type two diabetic patients was $28.7 \%$ [16]. There was a $36 \%$ prevalence of PAD among DM patients in India [11] whereas it was $24 \%$ in Uganda [8]. A prevalence of $22 \%$ was reported in Nigeria diabetic patients [26]. Age, gender, duration of diabetes mellitus, persistent hyperglycemia, increased glycated hemoglobin (HbA1c), smoking, hypertension, dyslipidemia, and obesity are associated with an increased risk of $\operatorname{PAD}[9,17,27]$. Among these, the most common risk factors associated with PAD are increasing age, diabetes, and smoking [26, 28, 29]. Early diagnosis and treatment of PAD in a diabetes patient are critically important for risk factor modification, reduction of its prevalence, progression and improvement of its outcome [17], improving quality of life, preventing cardiovascular events, and minimizing the risk of long-term disability and other complications associated with it $[16,30,31]$. However, most patients with PAD are asymptomatic and did not complain intermittent claudication due to decreased pain perception secondary to peripheral neuropathy [32, 33]. Of those who are symptomatic, only a small proportion of the diabetic population reports it due to a lack of awareness about symptoms of PAD [29]. This, in turn, delays the recognition and diagnosis of PAD [32]. These asymptomatic nature, lack of awareness, and underutilization of screening tools made PAD underestimated and untreated [16]. Even though diabetes is highly prevalent in Ethiopia, and results in major complications like PAD, nothing is known about the prevalence and associated factors of PAD among diabetes patients in Ethiopia. Therefore, this study is aimed at filling this gap by determining the prevalence and associated factors of PAD among T2DM patients at Debre Tabor General Hospital, Ethiopia. Furthermore, this study adds information to the scientific community and will serve as a baseline for future researchers.

\section{Methods and Materials}

2.1. Study Area and Period. An institution-based crosssectional study was conducted from the $1^{\text {st }}$ of February to the $30^{\text {th }}$ of August 2019 at Debre Tabor General Hospital in Debre Tabor town, which is located $667 \mathrm{~km}$ to the northwest of Addis Ababa, the capital city of Ethiopia.
2.2. Source and Study Population. All diabetes mellitus patients who were attending the diabetic follow-up clinic at Debre Tabor General Hospital were our source of population. This study included all type 2 diabetes patients aged $\geq 50$ years who attended the diabetic follow-up clinic at Debre Tabor General Hospital during the study period.

2.3. Inclusion and Exclusion Criteria. All T2DM patients aged $\geq 50$ years present during the study period were included. But T2DM patients who were severely ill; patients with lower limb swelling due to filariasis, inflammation, or other causes, which would impair the Doppler image quality; patients with a history of cardiovascular disease (CVD) including stroke; and patients with a history of hypertension before a diagnosis of DM were excluded from the study.

2.4. Sample Size and Sampling Procedure. The required sample size for the study was estimated using a single population proportion formula by taking a $24 \%$ proportion of PAD among diabetic patients of Uganda [8], 0.05 level of significance $(\alpha)$, and $5 \%$ margin of error. Accordingly, the final sample size for this study was 280 . We consecutively enrolled a total of 280 type two diabetic patients.

2.5. Data Collection Procedure. A pretested, intervieweradministered questionnaire was used to collect data. The questionnaire was adapted from previously published articles $[11,13,16,17,25,34-36]$, prepared in English and translated to Amharic, and retranslated to English by another person. To assess symptoms of PAD, intermittent claudication, we administered a validated Edinburgh Claudication Questionnaire (ECQ) [37]. Three data collectors and one supervisor participated in data collection. Data were also extracted from patient charts. Anthropometric measurements were taken using standardized techniques and calibrated equipment. Body weight $(\mathrm{kg})$ and height $(\mathrm{cm})$ were measured to the nearest $0.1 \mathrm{~cm}$ and $0.1 \mathrm{~kg}$, respectively, in barefoot subjects wearing light clothing. Body mass index (BMI) was calculated as weight divided by height squared $\left(\mathrm{kg} / \mathrm{m}^{2}\right)$. Blood pressure (BP) was recorded using a mercury sphygmomanometer BP cuff with the appropriate size that covers two-thirds of the arm with the subject in the sitting position. The arm which was used for BP measurement was supported on a flat table. Participants were asked to rest for at least 5 minutes, and if they were taking any caffeinated beverages, they were rested for 30 minutes before measurement. Two consecutive measurements were taken 5 minutes apart, and the mean value was used. HbA1c was measured using a 902 Automatic Analyzer with a Roche/Hitachi kit (Roach Diagnostic, USA).

2.5.1. Diagnosis of PAD. Diagnosis of PAD was made by using color Doppler ultrasound with sensitivity of $97 \%$, specificity of $81 \%$, and diagnostic accuracy of $85 \%$ [38]. To eliminate interobserver variation, a single senior radiologist performed all Doppler studies using color Doppler ultrasonography (Sonoscape SSI 8000). Grading of stenosis was made according to Jager's criteria.

2.6. Operational Definitions. PAD was defined as Grade III ( $50 \%$ to $99 \%$ stenosis) or IV stenosis ( $100 \%$ stenosis) by color 
Doppler ultrasonography [16]. Grade I is $1 \%$ to $19 \%$ stenosis: normal triphasic flow with normal peak systolic velocity with spectral broadening. Grade II is $20 \%$ to 49\% stenosis: a triphasic waveform with an increase in peak systolic velocity $=30 \%$ concerning the proximal recording site, marked spectral broadening. Grade III is 50\% to $99 \%$ stenosis: a monophasic waveform with an increase in peak systolic velocity $=100 \%$ and marked spectral broadening. The distal waveform is abnormal. Grade IV is $100 \%$ stenosis: no forward flow detected with altered flow patterns, both proximal and distal to the stenosis [39]. Hypertension (HTN) is systolic blood pressure (SBP) and/or Diastolic Blood Pressure (DBP) of 140/90 mmHg or greater [40]. Typical claudication was defined as the presence of calf pain, regardless of whether there was a pain at other sites. Atypical claudication was defined as having pain in the thigh or buttock in the absence of calf pain. No claudication was defined as having pain in the hamstrings, feet, shins, or joints; or any calf, thigh, or buttock pain that appears to radiate; or no pain at all in any part of the leg [37]. For body mass index, a person with a BMI of $18.5-24.9 \mathrm{~kg} / \mathrm{m}^{2}, 25-30 \mathrm{~kg} / \mathrm{m}^{2}$, and $>30 \mathrm{~kg} / \mathrm{m}^{2}$ is considered as normal, overweight, and obese, respectively. Ex-smokers were participants who did not currently smoke but had a history of cigarette smoking in their lifetime. Current smokers were defined as participants who smoked a cigarette at least once in the last month before the study.

2.7. Data Quality Control. To assure data quality, first, the questioner was pretested on 14 type 2 diabetes mellitus patients at another diabetic clinic (at Addis Zemen District Hospital). Data was collected under regular supervision after giving training for data collectors. Data were also properly entered and coded before analysis.

2.8. Data Processing and Analysis. Data were entered using EpiData-V.4.6 and analyzed by STATA-14. We expressed continuous data by the mean \pm standard deviation and categorical variables by percentages. The Chi-squared test was used, after checking its assumption, to examine the difference between categorical variables. Both binary and multivariable logistic regression analyses were performed to identify risk factors for PAD. Variables in bivariable analysis with $P<0.2$ were entered into multivariable logistic regression. In multivariable logistic regression, variables with $P \leq 0.05$ were declared statistically significant. Goodness of fit of the statistical model was checked by the Hosmer-Lemeshow test $(P=0.065)$. Furthermore, interaction of independent variables that were a candidate for the multivariable logistic regression model was checked. The strength of the association of risk factors with PAD was demonstrated by computing the crude odds ratio (COR) and the adjusted odds ratio (AOR) with a 95\% confidence interval (CI).

2.9. Ethical Consideration. Ethical approval for the study was obtained from the Institute of Public Health College of Medicine and Health Sciences, University of Gondar. Written informed consent was obtained from all study participants, and confidentiality was kept. All the study subjects had answered the administered pretested questionnaires voluntarily and confidently.

\section{Results}

3.1. Sociodemographic and Clinical Characteristics of Study Participants. The study was conducted on 280 T2DM patients. The mean age of the study participants was $61.2 \pm$ 7.3 , ranging from 50 to 91 years. One hundred seventy-two (61.4\%) patients were male. The majority $(70.4 \%)$ of study participants live in an urban area. Regarding educational status, $97(34.6 \%)$ study participants cannot read and write. Ninety-three (33.2\%) study participants were a governmental employee. Half of the study participants were diabetic for 1020 years. The majority $(73.2 \%)$ of the study participants were overweight. Two hundred fifteen (76.8\%) respondents use an oral hypoglycemic agent as a treatment option for T2DM. The mean HbAlc of respondents was $6.9 \pm 1.13$. Thirtynine (13.9\%) and twenty-nine (7.5\%) respondents were exsmoker and current cigarette smokers, respectively, while the remaining are nonsmokers. Regarding hypertension status, $160(57.1 \%)$ respondents were currently hypertensive, while $146(52.1 \%)$ had history of hypertension (Table 1).

3.2. Prevalence of PAD and Degree of Stenosis among T2DM Patients. The prevalence of PAD was $30.7 \%$ (95\% CI (25.3-36.2\%)); among these, 37 (43\%) were symptomatic. Of those who were symptomatic, $30(81.1 \%)$ had typical intermittent claudication (Table 2). Regarding the degree of stenosis, $162(27.8 \%)$ T2DM patients had no stenosis while the other 118 (43.2\%) have a different degree of stenosis (Figure 1).

3.3. Factors Associated with PAD among T2DM Patients. Crude association of all independent variables with the dependent variable PAD was checked by binary logistic regression. Accordingly, age, educational status, DM duration, BMI, type of antidiabetic drug on use, $\mathrm{HbAlc}$, cigarette smoking, history of hypertension (HTN), and current HTN were a candidate for the final model. After adjusting for potential confounders in the multivariable analysis, age, HbAlc, and cigarette smoking were significantly associated with PAD. A 1-year increase in age of DM patients was associated with a $9 \%$ higher odds (AOR $=1.09,95 \% \mathrm{CI}$ (1.03-1.16)) of PAD. Each 1\% increase in HbAlc was associated with 1.9 times $(\mathrm{AOR}=1.97,95 \% \mathrm{CI}(1.03-3.40))$ higher odds of developing PAD.

The odds of PAD among T2DM patients were 4.7 times higher $(\mathrm{AOR}=4.68,95 \% \mathrm{CI}(1.93-11.30))$ in ex-smokers than nonsmokers. Similarly, the odds of PAD among T2DM patients were 5.8 times $(\mathrm{AOR}=5.84,95 \% \mathrm{CI}(1.79$ 19.04)) higher in current smokers than nonsmokers (Table 3).

\section{Discussion}

A total of 250 diabetic patients were included in the study. Color Doppler ultrasound-proven prevalence of PAD among type 2 diabetics was $30.7 \%$. 
TABLE 1: Sociodemographic and clinical characteristics of T2DM patients, Debre Tabor, Northwest Ethiopia, 2019.

\begin{tabular}{|c|c|c|c|}
\hline Variable & Categories & Frequency/mean $\pm \mathrm{SD}$ & Percent \\
\hline Age $\left(\right.$ years) ${ }^{c}$ & & $61.2 \pm 7.3$ & \\
\hline \multirow{2}{*}{ Sex } & Male & 172 & 61.4 \\
\hline & Female & 108 & 38.6 \\
\hline \multirow{2}{*}{ Residence } & Urban & 197 & 70.4 \\
\hline & Rural & 83 & 29.6 \\
\hline \multirow{4}{*}{ Educational status } & Cannot read and write & 97 & 34.6 \\
\hline & Read and write & 57 & 20.4 \\
\hline & Elementary (1-8) & 48 & 17.2 \\
\hline & High school and above & 78 & 27.9 \\
\hline \multirow{5}{*}{ Occupation } & Farmer & 44 & 15.7 \\
\hline & Government employee & 93 & 33.2 \\
\hline & Merchant & 72 & 25.7 \\
\hline & Housewife & 62 & 22.1 \\
\hline & Other* & 9 & 3.2 \\
\hline \multirow{3}{*}{ DM duration (year) } & $<10$ & 119 & 42.5 \\
\hline & $10-19$ & 141 & 50.4 \\
\hline & $\geq 20+$ & 20 & 7.1 \\
\hline \multirow{3}{*}{ BMI $\left(\mathrm{kg} / \mathrm{m}^{2}\right)$} & Normal & 18 & 6.4 \\
\hline & Overweight & 205 & 73.2 \\
\hline & Obese & 57 & 20.4 \\
\hline \multirow{3}{*}{ Type of antidiabetic drug } & $\mathrm{OH}$ & 215 & 76.8 \\
\hline & Insulin & 21 & 7.5 \\
\hline & Both $\mathrm{OH}$ and insulin & 44 & 15.7 \\
\hline $\operatorname{HbAlc}(\%)^{\mathrm{c}}$ & & $6.9 \pm 1.13$ & \\
\hline \multirow{3}{*}{ Cigarette smoking } & Nonsmoker & 220 & 78.6 \\
\hline & Ex-smoker & 39 & 13.9 \\
\hline & Current smoker & 21 & 7.5 \\
\hline \multirow{2}{*}{ History of HTN self-reported } & Yes & 146 & 52.1 \\
\hline & No & 134 & 47.9 \\
\hline \multirow{2}{*}{ Current hypertension (high blood pressure) } & Yes & 160 & 57.1 \\
\hline & No & 120 & 42.9 \\
\hline
\end{tabular}

Other* ${ }^{*}$ daily laborer, nongovernmental organization workers; ${ }^{\mathrm{c}}$ continuous variables expressed as the mean $\pm \mathrm{SD} ; \mathrm{OH}=$ oral hypoglycemic agent.

TABle 2: Comparison of PAD symptoms between PAD-positive and PAD-negative DM patients, Debre Tabor, Northwest Ethiopia, 2019.

\begin{tabular}{lcccr}
\hline \multirow{2}{*}{ Symptom status } & Total & PAD $(N=86)$ & No PAD $(n=194)$ & \multicolumn{2}{c}{ Statistical significance } \\
& & $N(\%)$ & $N(\%)$ & $\chi^{2}$ \\
\hline Asymptomatic & $222(79.3 \%)$ & $49(22.1)$ & $173(77.9)$ & 37.6 \\
Symptomatic & $58(20.7 \%)$ & $37(63.8)$ & $21(36.2)$ & \\
Typical symptom & $35(12.5 \%)$ & $30(85.7)$ & $5(14.3)$ & 18.3 \\
Atypical symptom & $23(8.0 \%)$ & $7(30.4)$ & $16(69.5)$ & $P<0.0001$ \\
\hline
\end{tabular}

This high prevalence is a result of hyperglycemia, dyslipidemia, and insulin resistance, secondary to DM, which all induce development and progression of PAD or atherosclerosis by disrupting the vessel wall through promotion of vas- cular inflammation and endothelial cell dysfunction, derangements of various cell types like platelets within the vascular wall, promotion of coagulation, and inhibition of fibrinolysis [41]. This finding is in line with a finding of a 


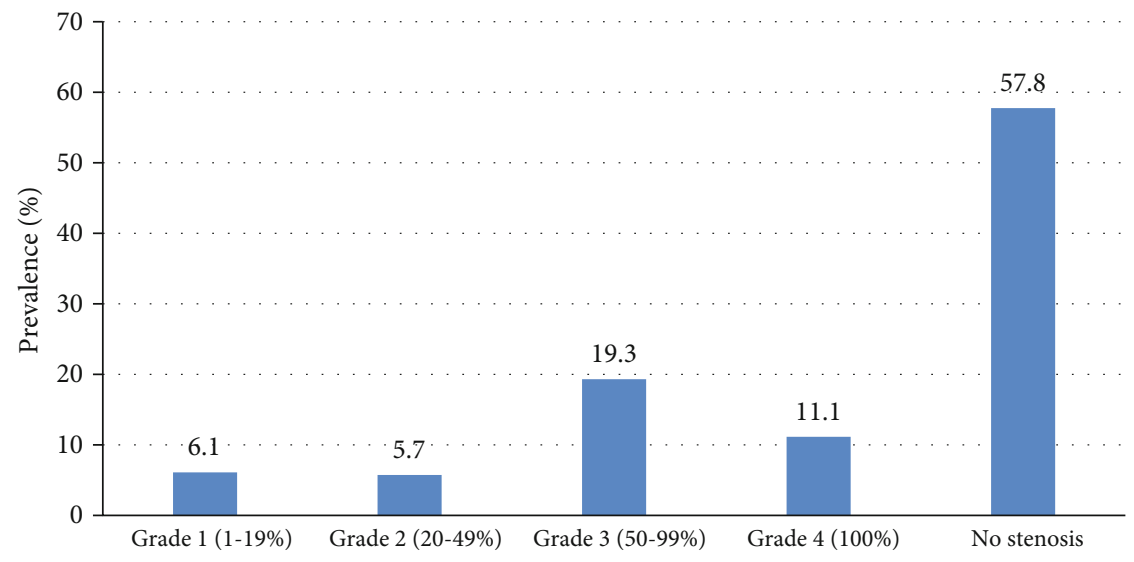

FIGURE 1: Degree of stenosis on color Doppler ultrasonography in patients with T2DM. Grade III and IV stenoses were defined as peripheral artery disease.

study done in the United States (29\%) [42], Korea (28.7\%) [16], Uttar Pradesh, India (36\%) [11], India (35\%) [43], and Pakistan (31.6\%) [43].

Nonetheless, the prevalence of PAD in the current study is higher than the result of a study done in Uganda (24\%) [8], Nigeria (22\%) [26], Coastal Karnataka, India (8.5\%) [13], and South India $(16.5 \%)[13,20]$. The possible reason for this difference might be due to a difference in the type of diagnostic tool used. Color Doppler ultrasound was used in the current study which is the best diagnostic technique compared with other diagnostic methods like the ankle-brachial index, which can underestimate the prevalence of PAD [16]. Another possible cause of difference may be a variation in the age of study participants, drug adherence, and management of T2DM. On the other hand, the prevalence of PAD in the current study is lower than that of the study done in Uganda (39\%) [44] and Pakistan (39.3\%) [45]. This might be due to a difference in socioeconomic factors, lifestyle, and duration of diabetes of study participants.

In the current study, age, $\mathrm{HbAlc}$, being an ex-smoker, and current cigarette smoking were significantly associated with PAD. Each 1-year increase in age of DM patients was associated with $9 \%$ higher odds of developing PAD. This is supported by a study done in Korea [16], Nigeria [26], Greece [17], Boston, United States [36], and India [11, 46]. The reason for an increase in the prevalence of PAD with an increase in age is due to the reason that with age, each layer of blood vessels changes in complex ways and triggers arterial stiffening and thickening. Thickening of the intima due to aging compromises endothelium integrity and decreases the availability of nitric oxide, a known vasodilator. Stiffening of the arterial walls disturbs the normal blood flow that makes it easier for calcium and fatty deposits to build upon the inside of arteries which leads to further fatty build-up and narrowing of the vessel resulting in PAD [47-49].

Each $1 \%$ increase in $\mathrm{HbAlc}$ was associated with 1.9 times higher odds of developing PAD. This finding was consistent with the findings of other studies $[17,50,51]$. This is because of the effect of the process of glycation. Since HbAlc is a compound synthesized from the nonenzymatic glycation reaction of glucose and hemoglobin, especially in poorly con- trolled diabetes [52], an increase in $\mathrm{HbAlc}$ is associated with increased glycation, nonenzymatic addition of glucose to amino groups of proteins, due to hyperglycemia. Glycation enhances the covalent binding of lipoproteins to vascular wall proteins, promoting sequestration, free radical release, and hence inducing inflammation which all lead to the development of atherosclerosis and PAD. Antithrombin III may also be glycated resulting in impairment of its function and increase in thrombotic tendency that in turn triggers atherosclerosis [53, 54]. Regarding cigarette smoking, the current study showed that the odds of PAD among T2DM patients were 5.8 and 4.7 times higher in the current smoker and ex-smokers, respectively, than nonsmokers. Consistently, a study done in the United States revealed that current smokers have 4 times more risk of PAD than that of nonsmokers [55]. Similarly, a study done in the United Kingdom showed that cigarette smoking can result in a sevenfold increase in the risk of peripheral arterial disease [56]. A study done in Korea [16] also revealed a similar result. The reason why smokers are more prone to $\mathrm{PAD}$ is due to the toxic effect of nicotine, carbon monoxide, and other ingredients in it on blood vessels. Nicotine impairs endothelium-dependent vasodilatation by reducing nitric oxide production [57]. Nicotine stimulates the release of catecholamine, which increases platelet aggregability and thrombosis. Platelets contribute to the growth of plaque through the accretion of thrombus. Nicotine also induces insulin resistance and dyslipidemia, vascular inflammation, abnormal vascular growth, and loss of endothelial homeostatic and regenerative functions. Also, nicotine has direct actions on the cellular elements participating in plaque formation. All these effects of nicotine predispose to peripheral arterial disease [58], as well as through the release of growth factors (such as platelet-derived relaxing factor) that induce vascular smooth muscle cell proliferation. Moreover, nicotine has direct actions on the cellular elements participating in plaque formation to increase plaque progression independently of plasma lipid values [59,60]. In addition to nicotine, free radicals directly from the component of cigarette smoke or activation of endogenous source free radicals lead to oxidative stress which is a major contributor to atherosclerosis and peripheral arterial disease [61]. 
TABLE 3: Factors associated with PAD among type 2 diabetes mellitus patients in bivariable and multivariable logistic regression analyses, Debre Tabor, Northwest Ethiopia, 2019.

\begin{tabular}{|c|c|c|c|c|}
\hline \multirow{2}{*}{ Variable } & \multicolumn{2}{|c|}{ PAD } & \multicolumn{2}{|c|}{ OR $(95 \%$ CI $)$} \\
\hline & Yes $(n=86)$ & No $(n=194)$ & COR & AOR \\
\hline Age $(\text { year })^{\mathrm{C}}$ & $64.7 \pm 8.9$ & $59.6 \pm 5.8$ & $1.11(1.06-1.15)$ & $1.09(1.03-1.16)^{* *}$ \\
\hline \multicolumn{5}{|l|}{ Sex } \\
\hline Male & $57(33.1)$ & $115(66.9)$ & $1.35(0.80-2.30)$ & \\
\hline Female & $29(26.9)$ & $79(73.1)$ & 1 & \\
\hline \multicolumn{5}{|l|}{ Residence } \\
\hline Urban & $63(31.9)$ & $134(68.1)$ & $1.23(0.70-2.16)$ & \\
\hline Rural & $23(27.7)$ & $60(72.3)$ & 1 & 1 \\
\hline \multicolumn{5}{|l|}{ Educational status } \\
\hline Cannot read and write & $24(24.7)$ & $73(75.3)$ & $0.84(0.43-1.65)$ & $1.27(0.56-2.95)$ \\
\hline Read and write & $18(31.6)$ & $39(68.4)$ & $1.17(0.56-2.47)$ & $1.12(0.46-2.73)$ \\
\hline Elementary (1-8) & $22(45.8)$ & $26(54.2)$ & $2.15(1.02-4.57)$ & $1.39(0.54-3.62)$ \\
\hline High school and above & $22(28.2)$ & $56(71.8)$ & 1 & \\
\hline \multicolumn{5}{|l|}{ Occupation } \\
\hline Farmer & $12(27.3)$ & $32(72.7)$ & 1 & \\
\hline Government employee & $29(31.1)$ & $64(68.8)$ & $1.2(0.55-2.68)$ & \\
\hline Merchant & $26(36.1)$ & $46(63.9)$ & $1.50(0.66-3.42)$ & \\
\hline Housewife & $17(27.4)$ & $45(72.6)$ & $1.00(0.42-2.40)$ & \\
\hline Other & $2(77.8)$ & $7(22.2)$ & $0.76(0.14-4.20)$ & \\
\hline \multicolumn{5}{|l|}{ DM duration } \\
\hline Year $<10$ & $22(18.5)$ & $97(81.5)$ & 1 & \\
\hline $10-19$ & $51(36.2)$ & $90(63.8)$ & $2.50(1.40-4.45)$ & \\
\hline$\geq 20$ & $13(65.0)$ & $7(35.0)$ & $8.18(2.92-22.90)$ & \\
\hline \multicolumn{5}{|l|}{$\operatorname{BMI}\left(\mathrm{kg} / \mathrm{m}^{2}\right)$} \\
\hline Normal & $12(66.7)$ & $6(33.3)$ & 1 & \\
\hline Overweight & $55(26.8)$ & $150(73.2)$ & $0.10(0.03-0.33)$ & $0.64(0.17-2.41)$ \\
\hline Obese & $19(33.3)$ & $38(66.7)$ & $10.36(0.10-1.27)$ & $1.50(0.34-6.70)$ \\
\hline \multicolumn{5}{|c|}{ Type of antidiabetic drug in use } \\
\hline $\mathrm{OH}$ & $49(22.8)$ & $166(77.2)$ & $0.39(0.16-0.98)$ & $0.37(0.13-1.11)$ \\
\hline Both $\mathrm{OH}$ and insulin & $28(63.6)$ & $16(36.4)$ & $2.33(0.81-6.74)$ & $0.98(0.26-3.66)$ \\
\hline Insulin & $9(42.9)$ & $12(57.1)$ & 1 & \\
\hline $\operatorname{HbAlc}(\%)^{\mathrm{C}}$ & $7.6 \pm 1.2$ & $6.6 \pm 0.9$ & $2.04(1.48-2.83)$ & $1.97(1.03-3.40)^{*}$ \\
\hline \multicolumn{5}{|l|}{ Cigarette smoking } \\
\hline Nonsmoker & $49(22.3)$ & $171(77.7)$ & 1 & \\
\hline Ex-smoker & $23(59.0)$ & $16(41.0)$ & $5.02(2.46-10.23)$ & $4.68(1.93-11.30)^{* *}$ \\
\hline Current smoker & $14(66.7)$ & $7(33.3)$ & $6.98(2.67-18.25)$ & $5.84(1.79-19.04)^{* *}$ \\
\hline \multicolumn{5}{|c|}{ History of HTN self-reported } \\
\hline Yes & $46(31.5)$ & $100(68.5)$ & $1.08(0.65-1.79)$ & \\
\hline No & $40(29.9)$ & $94(70.1)$ & 1 & \\
\hline \multicolumn{5}{|c|}{ Current hypertension/high BP } \\
\hline Yes & $64(40)$ & $96(60)$ & $2.96(1.69-5.20)$ & $1.91(0.88-4.15)$ \\
\hline No & $22(18.3)$ & $98(81.7)$ & 1 & \\
\hline
\end{tabular}

${ }^{*}$ Statistically significant $(P$ value $<0.05) .{ }^{* *}$ Statistically highly significant $(P$ value $<0.01)$. AOR: adjusted odds ratio; CI: confidence interval; COR: crude odds ratio. ${ }^{\mathrm{C}}$ Continuous.

In this study, sex, current high blood pressure, duration of DM, type of antidiabetic drug in use, and BMI were not significantly associated with PAD. This is in contrary to other studies which showed that female sex $[8,20,62]$, current high blood pressure, being on a sulfonylurea-glibenclamide [8], duration of DM [20,63], and BMI [36] are significantly 
associated with PAD. This disagreement might be due to a difference in characteristics of study population, sample size, drug adherence, and study design.

4.1. Limitation of the Study. This study had limitations that should be considered. Since the study participants were taken only from a single diabetes center, the findings may not represent that of the general diabetes population. Even though the use of antiplatelet agent drugs may affect vascular function, we were unable to find data about it. Despite these limitations, we determined PAD using color Doppler ultrasonography, which is the best imaging technique to detect PAD without any side effects.

\section{Conclusion}

The prevalence of PAD among diabetes patients was high. Age, $\mathrm{HbAlc}$, and cigarette smoking were significantly associated with PAD. Clinicians should prevent PAD; screen all T2DM patients especially those aged, with high $\mathrm{HbAlc}$, and cigarette smokers; and treat them timely. A large-scale study, involving lipid profile and other important laboratory assessments, should be done on multiple diabetic centers.

\section{Abbreviations}

ABI: Ankle-brachial index

BMI: $\quad$ Body mass index

HbA1c: Glycated hemoglobin

HTN: Hypertension

PAD: Peripheral arterial disease

T2DM: Type 2 diabetes mellitus.

\section{Data Availability}

The data will be available from the corresponding author upon request.

\section{Conflicts of Interest}

The authors declare that they have no competing interests.

\section{Authors' Contributions}

YA designed the study, performed data analysis, and drafted the manuscript. $A B$ was involved in designing the study and data analysis and reviewed the manuscript. Both authors read and approved the final manuscript.

\section{Acknowledgments}

We would like to thank Debre Tabor General Hospital staff at the diabetic clinic for their support. The study participants are duly acknowledged for kindly giving us the required data.

\section{References}

[1] Association American Diabetes, "Updates to theStandards of Medical Care in Diabetes-2018," Diabetes Care, vol. 41, no. 9, pp. 2045-2047, 2018.
[2] World Health Organisation, Global Report on Diabetes, 2018, https://apps.who.int/iris/bitstream/handle/10665/204871/ 9789241565257_eng.pdf;jsessionid= 50535D02DE364CB414BD3FB8C5164E78? sequence $=1$.

[3] B. B. Bekele, "The prevalence of macro and microvascular complications of DM among patients in Ethiopia 1990-2017: Systematic review," Diabetes and Metabolic Syndrome: Clinical Research and Reviews, vol. 13, no. 1, pp. 672-677, 2019.

[4] International Diabetes Federation, IDF Diabetes Atlas, 8th edition, 2017, https://www.idf.org/e-library/epidemiologyresearch/diabetes-atlas.

[5] M. A. Munger and D. W. Hawkins, "Atherothrombosis: epidemiology, pathophysiology, and prevention," Journal of the American Pharmacists Association, vol. 44, no. 2, pp. S5-13, 2004.

[6] M. D. Silvio Inzucchi, M. D. Richard Bergenstal, M. D. Vivian Fonseca et al., "ADA position statement on the diagnosis and classification of diabetes mellitus," Diabetes Care, vol. 33, Supplement 1, pp. S62-S69, 2010.

[7] H. El, D. Mohamed, M. Elsheikh, H. Barakat, and A. F. Abdelhamid, "A comparative study of mesh fixation versus nonfixation in laparoscopic totally extraperitoneal inguinal hernia repair," The Egyptian Journal of Surgery, vol. 38, no. 2, pp. 348-355, 2019.

[8] S. Okello, A. Millard, R. Owori et al., "Prevalence of lower extremity peripheral artery disease among adult diabetes patients in southwestern Uganda," BMC Cardiovascular Disorders, vol. 14, no. 1, p. 75, 2014.

[9] M. H. Criqui and V. Aboyans, "Epidemiology of peripheral artery disease," Circulation Research, vol. 116, no. 9, pp. 1509-1526, 2015.

[10] J. W. Olin and B. A. Sealove, "Peripheral artery disease: current insight into the disease and its diagnosis and management," Mayo Clinic Proceedings, vol. 85, no. 7, pp. 678-692, 2010.

[11] V. Shukla, J. Fatima, M. Ali, and A. Garg, "A study of prevalence of peripheral arterial disease in type 2 diabetes mellitus patients in a teaching hospital," The Journal of the Association of Physicians of India, vol. 66, no. 5, pp. 57-60, 2018.

[12] B. Sigvant, P. Hasvold, B. Kragsterman et al., "Cardiovascular outcomes in patients with peripheral arterial disease as an initial or subsequent manifestation of atherosclerotic disease: results from a Swedish nationwide study," Journal of Vascular Surgery, vol. 66, no. 2, pp. 507-514.e1, 2017.

[13] E. Arora, A. G. Maiya, T. Devasia, R. Bhat, and G. Kamath, "Prevalence of peripheral arterial disease among type 2 diabetes mellitus in coastal Karnataka," Diabetes and Metabolic Syndrome: Clinical Research and Reviews, vol. 13, no. 2, pp. 1251-1253, 2019.

[14] A. N. Shammas, H. Jeon-Slaughter, S. Tsai et al., "Major limb outcomes following lower extremity endovascular revascularization in patients with and without diabetes mellitus," Journal of Endovascular Therapy, vol. 24, no. 3, pp. 376-382, 2017.

[15] C. Natsuaki, T. Inoguchi, Y. Maeda et al., "Association of borderline ankle-brachial index with mortality and the incidence of peripheral artery disease in diabetic patients," Atherosclerosis, vol. 234, no. 2, pp. 360-365, 2014.

[16] K. Y. Hur, J. E. Jun, Y. J. Choi et al., “Color doppler ultrasonography is a useful tool for diagnosis of peripheral artery disease in type 2 diabetes mellitus patients with ankle-brachial index 0.91 to 1.40 ," Diabetes and Metabolism Journal, vol. 42, no. 1, pp. 63-73, 2018. 
[17] E. B. Jude, I. Eleftheriadou, and N. Tentolouris, "Peripheral arterial disease in diabetes - a review," Diabetic Medicine, vol. 27, no. 1, pp. 4-14, 2010.

[18] R. Goyena, "Screening for adrenal antibodies in children with type 1 diabetes and autoimmune thyroid disease," Journal of Chemical Information and Modeling, vol. 53, no. 9, pp. 16891699, 2019.

[19] D. T. Williams, P. Price, and K. G. Harding, "Amputation and mortality in new-onset diabetic foot ulcers stratified by etiology: response to Moulik, Mtonga, and Gill," Diabetes Care, vol. 26, no. 11, pp. 3199-3200, 2003.

[20] J. Eshcol, S. Jebarani, R. M. Anjana, V. Mohan, and R. Pradeepa, "Prevalence, incidence and progression of peripheral arterial disease in Asian Indian type 2 diabetic patients," Journal of Diabetes and its Complications, vol. 28, no. 5, pp. 627-631, 2014.

[21] E. B. Jude, S. O. Oyibo, N. Chalmers, and A. J. M. Boulton, "Peripheral arterial disease in diabetic and nondiabetic patients: a comparison of severity and outcome," Diabetes Care, vol. 24, no. 8, pp. 1433-1437, 2001.

[22] E. W. Gregg, P. Sorlie, R. Paulose-Ram et al., "Prevalence of lower-extremity disease in the US adult population $\geq 40$ years of age with and without diabetes: 1999-2000 national health and nutrition examination survey," Diabetes Care, vol. 27, no. 7, pp. 1591-1597, 2004.

[23] C. W. Yancy, M. Jessup, B. Bozkurt et al., "2016 ACC/AHA/HFSA Focused Update on New Pharmacological Therapy for Heart Failure: An Update of the 2013 ACCF/AHA Guideline for the Management of Heart Failure: A Report of the American College of Cardiology/American Heart Association Task Force on Clinical Practice Guidelines and the Heart Failure Society of America," Journal of Cardiac Failure, vol. 22, no. 9, pp. 659-669, 2016.

[24] C. W. Yancy, M. Jessup, B. Bozkurt et al., "2016 ACC/AHA/HFSA Focused Update on New Pharmacological Therapy for Heart Failure: An Update of the 2013 ACCF/AHA Guideline for the Management of Heart Failure: A Report of the American College of Cardiology/American Heart Association Task Force on Clinical Practice Guidelines and the Heart Failure Society of America," Journal of the American College of Cardiology, vol. 68, no. 13, pp. 1476-1488, 2016.

[25] R. Willam and T. Hiat, "Medical treatment of peripheral arterial disease and claudication W," English Journal, vol. 344, no. 21, pp. 1608-1621, 2005.

[26] D. O. Soyoye, R. T. Ikem, B. A. Kolawole, K. S. Oluwadiya, R. A. Bolarinwa, and O. J. Adebayo, "Prevalence and correlates of peripheral arterial disease in Nigerians with type 2 diabetes," Advances in Medicine, vol. 2016, Article ID 3529419, 6 pages, 2016.

[27] L. H. Eraso, E. Fukaya, E. R. Mohler III, D. Xie, D. Sha, and J. S. Berger, "Peripheral arterial disease, prevalence and cumulative risk factor profile analysis," European Journal of Preventive Cardiology, vol. 21, no. 6, pp. 704-711, 2014.

[28] L. Norgren, W. R. Hiatt, K. A. Harris, and J. Lammer, "TASC II section $\mathrm{F}$ on revascularization in PAD," Journal of Endovascular Therapy, vol. 14, no. 5, pp. 743-744, 2007.

[29] A. W. Pollak and C. M. Kramer, "MRI in lower extremity peripheral arterial disease: recent advancements," Current Cardiovascular Imaging Reports, vol. 6, no. 1, pp. 55-60, 2013.

[30] D. L. Bhatt, P. G. Steg, E. M. Ohman et al., "International prevalence, recognition, and treatment of cardiovascular risk fac- tors in outpatients with atherothrombosis," Journal of the American Medical Association, vol. 295, no. 2, pp. 180-189, 2006.

[31] S. P. Marso and W. R. Hiatt, "Peripheral arterial disease in patients with diabetes," Journal of the American College of Cardiology, vol. 47, no. 5, pp. 921-929, 2006.

[32] E. B. Jude, "Intermittent claudication in the patient with diabetes," The British Journal of Diabetes \& Vascular Disease, vol. 4, no. 4, pp. 238-242, 2004.

[33] G. Dhaliwal and D. Mukherjee, "Peripheral arterial disease: epidemiology, natural history, diagnosis and treatment," International Journal of Angiology, vol. 16, no. 2, pp. 36-44, 2007.

[34] A. Fasil, B. Biadgo, and M. Abebe, "Glycemic control and diabetes complications among diabetes mellitus patients attending at University of Gondar Hospital, Northwest Ethiopia," Diabetes, Metabolic Syndrome and Obesity: Targets and Ther$a p y$, vol. 12, pp. 75-83, 2019.

[35] E. Selvin and T. P. Erlinger, "Prevalence of and risk factors for peripheral arterial disease in the United States: results from the National Health and Nutrition Examination Survey, 19992000," Circulation, vol. 110, no. 6, pp. 738-743, 2004.

[36] J. M. Murabito, J. C. Evans, K. Nieto, M. G. Larson, D. Levy, and P. W. F. Wilson, "Prevalence and clinical correlates of peripheral arterial disease in the Framingham Offspring Study," American Heart Journal, vol. 143, no. 6, pp. 961-965, 2002.

[37] G. C. Lend and F. G. R. Fowkes, "The Edinburgh Claudication Questionnaire: an improved version of the WHO/Rose questionnaire for use in epidemiological surveys," Journal of Clinical Epidemiology, vol. 45, no. 10, pp. 1101-1109, 1992.

[38] J. E. A. Lewis, P. Williams, and J. H. Davies, "Non-invasive assessment of peripheral arterial disease : automated ankle brachial index measurement and pulse volume analysis compared to duplex scan," SAGE Open Medicine, vol. 4, 2016.

[39] K. A. Jager, D. J. Phillips, R. L. Martin et al., "Noninvasive mapping of lower limb arterial lesions," Ultrasound in Medicine \& Biology, vol. 11, no. 3, pp. 515-521, 1985.

[40] B. Williams, G. Mancia, W. Spiering et al., "ESC/ESH guidelines for themanagement of arterial hypertension," Journal of Hypertension, vol. 36, pp. 1956-2041, 2018.

[41] T. Thiruvoipati, C. E. Kielhorn, and E. J. Armstrong, "Peripheral artery disease in patients with diabetes: epidemiology, mechanisms, and outcomes," World Journal of Diabetes, vol. 6, no. 7, pp. 961-969, 2015.

[42] A. T. Hirsch, M. H. Criqui, D. Treat-Jacobson et al., "Peripheral arterial disease detection, awareness, and treatment in primary care," Journal of the American Medical Association, vol. 286, no. 11, pp. 1317-1324, 2001.

[43] P. B. Hathila, "Assessment of ankle brachial index in diabetic patients in urban area of West India," International Journal of Basic \& Applied Physiology, vol. 1, no. 1, pp. 114-119, 2012.

[44] R. M. Mwebaze and D. Kibirige, "Peripheral arterial disease among adult diabetic patients attending a large outpatient diabetic clinic at a national referral hospital in Uganda: a descriptive cross sectional study," PLoS One, vol. 9, no. 8, article e105211, 2014.

[45] Z. Ali, S. M. Ahmed, A. R. Bhutto, A. Chaudhry, and S. M. Munir, "Peripheral artery disease in type II diabetes," Journal of the College of Physicians and Surgeons-Pakistan : JCPSP, vol. 22, no. 11, pp. 686-689, 2012. 
[46] B. Doza, M. Kaur, S. Chopra, and R. Kapoor, "Cardiovascular risk factors and distributions of the ankle-brachial index among type 2 diabetes mellitus patients," International Journal of Hypertension, vol. 2012, Article ID 485812, 6 pages, 2012.

[47] National institute on aging, Aging hearts and arteries a scientific quest. Research on Aging, p. 68, 2005, https://www.google .com/url? sa $=$ t\&rct=j\&q=\&esrc $=$ s\&source $=$ web \&cd $=1 \& c a d=$ rja\&uact $=8 \&$ ved $=2$ ahUKEwjZhfwip7nAhXEy6QKHYEAB0oQFjAAegQIBRAB\&url=https\% 3A\%2F\%2Fcdn11.g5search.com\%2Fassets\%2F303305\% 2FAging_Hearts_and_Arteries.pdf\%3F1415902528\&usg= AOvVaw00TbxYdf3YG33KpFPVgmS-.

[48] J. C. Kohn, M. C. Lampi, and C. A. Reinhart-King, "Agerelated vascular stiffening: causes and consequences," Frontiers in Genetics, vol. 6, p. 112, 2015.

[49] T. Head, S. Daunert, and P. J. Goldschmidt-Clermont, “The aging risk and atherosclerosis: a fresh look at arterial homeostasis," Frontiers in Genetics, vol. 8, p. 216, 2017.

[50] E. Selvin, S. Marinopoulos, G. Berkenblit et al., "Meta-analysis: glycosylated hemoglobin and cardiovascular disease in diabetes mellitus," Annals of Internal Medicine, vol. 141, no. 6, p. $421,2004$.

[51] P. Muntner, R. P. Wildman, K. Reynolds, K. B. DeSalvo, J. Chen, and V. Fonseca, "Relationship between $\mathrm{HbA}_{1 \mathrm{c}}$ level and peripheral arterial disease," Diabetes Care, vol. 28, no. 8, pp. 1981-1987, 2005.

[52] S. P. Palem, "HbA1c is a risk factor for cardiovascular disease in association with oxidative stress in patients with type 2 diabetes mellitus," International Journal of Research in Medical Sciences, vol. 5, no. 7, p. 3114, 2017.

[53] T. J. Lyons, "Glycation and oxidation: a role in the pathogenesis of atherosclerosis," The American Journal of Cardiology, vol. 71, no. 6, pp. B26-B31, 1993.

[54] N. Katakami, "Mechanism of development of atherosclerosis and cardiovascular disease in diabetes mellitus," Journal of Atherosclerosis and Thrombosis, vol. 25, no. 1, pp. 27-39, 2018.

[55] E. Selvin and A. T. Hirsch, "Contemporary risk factor control and walking dysfunction in individuals with peripheral arterial disease: NHANES 1999-2004," Atherosclerosis, vol. 201, no. 2, pp. 425-433, 2009.

[56] J. F. Price, P. I. Mowbray, A. J. Lee, A. Rumley, G. D. Lowe, and F. G. Fowkes, "Relationship between smoking and cardiovascular risk factors in the development of peripheral arterial disease and coronary artery disease: Edinburgh Artery Study," European Heart Journal, vol. 20, no. 5, pp. 344-353, 1999.

[57] P. Sleight, "Smoking and hypertension," Clinical and Experimental Hypertension, vol. 15, no. 6, pp. 1181-1192, 1993.

[58] A. D. Flouris, C. I. Vardavas, G. S. Metsios, A. M. Tsatsakis, and Y. Koutedakis, "Biological evidence for the acute health effects of secondhand smoke exposure," American Journal of Physiology. Lung Cellular and Molecular Physiology, vol. 298, no. 1, pp. L3-L12, 2010.

[59] C. Heeschen, J. J. Jang, M. Weis et al., "Nicotine stimulates angiogenesis and promotes tumor growth and atherosclerosis," Nature Medicine, vol. 7, no. 7, pp. 833-839, 2001.

[60] J. Lee and J. P. Cooke, "The role of nicotine in the pathogenesis of atherosclerosis," Atherosclerosis, vol. 215, no. 2, pp. 281283, 2011.

[61] J. A. Ambrose and R. S. Barua, "The pathophysiology of cigarette smoking and cardiovascular disease: an update," Journal of the American College of Cardiology, vol. 43, no. 10, pp. 1731-1737, 2004.

[62] V. Aboyans, M. H. Criqui, R. L. McClelland et al., "Intrinsic contribution of gender and ethnicity to normal anklebrachial index values: The Multi-Ethnic Study of Atherosclerosis (MESA)," Journal of Vascular Surgery, vol. 45, no. 2, pp. 319-327, 2007.

[63] A. Khurana, P. Dhoat, and T. S. Marwaha, "Peripheral vascular disease - a silent assassin: its rising trend in Punjab," Journal, Indian Academy of Clinical Medicine, vol. 14, no. 2, pp. 111114, 2013. 